Research articles

\title{
A new class of ferromagnetic semiconductor: Copper molybdate organic- inorganic compound with phenanthroline organic linkers
}

\author{
Islah-u-din $^{\mathrm{a}, \mathrm{d}, *}$, Shen V. Chong ${ }^{\mathrm{b}, \mathrm{c}}$, Geoffrey B. Jameson ${ }^{\mathrm{b}, \mathrm{d}}$, Sebastiampillai G. Raymond ${ }^{\mathrm{e}}$, \\ Geunsik Lee ${ }^{\mathrm{f}}$, In K. Park ${ }^{\mathrm{f}}$, Xiaolin Wang ${ }^{\mathrm{g}}$, Mark R. Waterland ${ }^{\mathrm{b}, \mathrm{d}}$, Jeffery L. Tallon ${ }^{\mathrm{b}, \mathrm{c}}$ \\ ${ }^{a}$ Department of Physics, Government College University Lahore, 54000 Lahore, Pakistan \\ ${ }^{\mathrm{b}}$ MacDiarmid Institute for Advanced Materials and Nanotechnology, Victoria University of Wellington, Wellington 6140, New Zealand \\ ${ }^{\mathrm{c}}$ Robinson Research Institute, Victoria University of Wellington, Lower Hutt 5010, New Zealand \\ ${ }^{\mathrm{d}}$ School of Fundamental Sciences, Massey University, Palmerston North 4442, New Zealand \\ ${ }^{\mathrm{e}}$ Advanced Materials Group, Callaghan Innovation, Lower Hutt 5010, New Zealand \\ ${ }^{\mathrm{f}}$ Department of Chemistry, Ulsan National Institute of Science and Technology, Ulsan 44919, South Korea \\ ${ }^{\mathrm{g}}$ Spintronic and Electronic Materials Group, Institute for Superconducting \& Electronic Materials, Australian Institute for Innovative Materials, University of Wollongong, \\ Wollongong, NSW 2500, Australia
}

\section{A R T I C L E I N F O}

\section{Keywords:}

Magnetic properties

Layered compounds

Organic-inorganic hybrids

Doping

Polycyclic aromatic hydrocarbons

\begin{abstract}
A B S T R A C T
A three-dimensional (3D) framework of covalently-bonded layers of bimetallic inorganic oxide, $\mathrm{CuMoO}_{4}$, interlinked by electron-rich organic ligands, which is semiconducting and also ferromagnetic, has been prepared. The structure $\left[\mathrm{Cu}(3,8 \text {-phenanthroline })_{0.5} \mathrm{MoO}_{4}\right]$ consists of molybdate tetrahedra corner-shared with clusters of edge-sharing $\left\{\mathrm{CuO}_{5} \mathrm{~N}\right\}$ octahedra. The injection of charge carriers into the inorganic layers by phenanthroline induces different magnetic orderings at different temperatures, orderings which are not found in the structurallysimilar $\left[\mathrm{Cu}\left(4,4^{\prime} \text {-bipyridine }\right)_{0.5} \mathrm{MoO}_{4}\right]$. The temperature dependence of the susceptibility shows two low temperature magnetic transitions: weakly ferromagnetic-coupled spins below $15 \mathrm{~K}$ coexisting with an antiferromagnetic structure below $10 \mathrm{~K}$. Specific heat capacity shows a finite ground-state electronic specific heat coefficient, $\gamma=0.094 \mathrm{~J} / \mathrm{mol} \cdot \mathrm{K}^{2}$, that is higher than that of the bipyridine counterpart $\left(0.068 \mathrm{~J} / \mathrm{mol} \cdot \mathrm{K}^{2}\right)$, confirming an increase in the electronic density-of-states in the phenanthroline system.
\end{abstract}

\section{Introduction}

Organic compounds are well-known for their flexibility, processability, and often relatively low cost. On the other hand, the excellent electronic, optical, magnetic and transport properties of inorganic materials make them highly desirable for practical applications. During the past decades, the integration of these two counterparts into organicinorganic "hybrid" crystalline materials has produced unprecedented features and properties not possible with either constituent alone [1-10]. This is well demonstrated, for example, in the metal-halide perovskites which display strong light absorption and high carrier mobility resulting in high power conversion efficiencies for photovoltaic applications [9-12].

Copper molybdates $\left(\mathrm{CuMoO}_{4}\right)$ have potential for many applications. These include catalytic oxidation of soot from diesel engine exhaust [13] and propene [14], thermochromics and piezochromic indicators [15-17]. The two latter properties are unique to $\mathrm{CuMoO}_{4}$ as it has different polymorphs and displays first-order phase transitions ( $\alpha$ - to $\gamma$ phase) accompanied by changes to the unit cell volume, electrical conductivity, magnetic properties and colour [17-20]. The difference in colour for each phase has been explained by charge-transfer band broadening and crystal field transition in the $\mathrm{Cu}-\mathrm{O}$ complexes $[18,19]$. Macroscopically, this is associated with the orientation and bond lengths of the $\mathrm{Cu}-\mathrm{O}$ polyhedra, where the coordination number of the $\mathrm{Cu}$ cation is five (pyramidal coordination) or six (octahedral coordination) [20]. The proximity and arrangement of the $\mathrm{Cu}^{2+}$ ions in the $\mathrm{CuMoO}_{4}$ polymorphs also have marked effects on their magnetic properties. The ambient condition $\alpha-\mathrm{CuMoO}_{4}$, which has isolated clusters of six $\mathrm{Cu}-\mathrm{O}$ polyhedra, and the low temperature (ambient pressure) $\gamma-\mathrm{CuMoO}_{4}$, where the $\mathrm{Cu}-\mathrm{O}$ polyhedra take on a one-dimensional chain-like connectivity within the $\boldsymbol{a}-\boldsymbol{b}$ plane [20,21], only displays long-range magnetic ordering below $2 \mathrm{~K}[21,22]$. In the $\varepsilon$ $\mathrm{CuMoO}_{4}$ polymorph all the $\mathrm{Cu}$-oxides are in $\mathrm{CuO}_{5}$ square pyramids and are edge-shared, forming $\mathrm{Cu}^{2+}$ "tetramers" with short $\mathrm{Cu}^{2+}-\mathrm{Cu}^{2+}$

\footnotetext{
* Corresponding author at: Department of Physics, Government College University Lahore, Pakistan.

E-mail address: islahudin@gcu.edu.pk (Islah-u-din).
} 
distances. The direct result of this is a ferromagnetic ordered state in this $\varepsilon$-phase with $T_{\text {curie }} \sim 10 \mathrm{~K}$ [23].

There is also another class of copper molybdates in the form of organic-inorganic hybrids with two-dimensional $\left\{\mathrm{CuMoO}_{4}\right\}$ layers and $\mathrm{N}$-containing ligands, $\left[\mathrm{Cu}(L)_{x} \mathrm{MoO}_{4}\right]$ (where $L=$ organic ligand) [24-33]. In [Cu(4,4'-bipyridine $\left.)_{0.5} \mathrm{MoO}_{4}\right] \cdot 1.5 \mathrm{H}_{2} \mathrm{O}$, tetranuclear units of edge-sharing $\mathrm{Cu}^{2+}$-containing octahedra are found, which induce antiferromagnetic interactions with a broad magnetization peak at $40 \mathrm{~K}$ [32]. Unlike the $\varepsilon$-CuMoO${ }_{4}$ polymorph, which contains shorter $\mathrm{Cu}^{2+}$ $\mathrm{Cu}^{2+}$ distance tetramers, no ferromagnetic ordering was reported in this tetramer-containing hybrid down to $2 \mathrm{~K}$ [32]. Of all the [Cu $\left.(L)_{x} \mathrm{MoO}_{4}\right]$ bimetallic hybrids reported in the literature, only $\left[\mathrm{Cu}\left(3,4^{\prime}-\right.\right.$ bipyridine) $\mathrm{MoO}_{4}$ ] displays ferromagnetic ordering above $13 \mathrm{~K}$ [32]. The coordination and arrangement of this latter hybrid is different from that of $\left[\mathrm{Cu}\left(4,4^{\prime} \text {-bipyridine }\right)_{0.5} \mathrm{MoO}_{4}\right] \cdot 1.5 \mathrm{H}_{2} \mathrm{O}$ Moreover, it is unclear which of the copper chains, running along the crystallographic $a$ or $b$ directions, is responsible for this ferromagnetic interaction [32]. Together, these results show that the geometric arrangement of the $\mathrm{Cu}^{2+}$ polyhedra, which can be strongly influenced by the type of N-containing organic ligands used, is an important factor in determining the final magnetic behaviour of $\left[\mathrm{Cu}(L)_{x} \mathrm{MoO}_{4}\right]$ hybrids. Moreover, subtle variations in the synthesis conditions (temperature, concentration and catalysts used) can influence the final hierarchical structures obtained, even when the same ligands are used. For example, for $\left[\mathrm{Cu}\left(4,4^{\prime}\right.\right.$-bipyridine) $\mathrm{MoO}_{4}$ ] the use of different reactant concentrations and synthesis temperature produced a hybrid without the tetranuclear edgesharing $\mathrm{Cu}^{2+}$ octahedra [27], and presumably does not display long range magnetic order.

A less explored route is how the doping of extra carriers in $\mathrm{CuMoO}_{4}$ in the hybrid and non-hybrid forms [32-34] can change their magnetic properties. Here we posit the question as to whether the presence of extra free carriers in the system, specifically in the hybrid form of $\mathrm{CuMoO}_{4}$, can influence the magnetic ground state in this system, and hence to some extent dilute the influence of the structural effects. We have previously shown that phenanthroline-based organic spacer molecules have the ability to increase the electronic density-of-states in $\mathrm{MoO}_{3}$-based layered hybrids [35]. The discovery of superconductivity in polycyclic aromatic hydrocarbons (PAHs) in alkali metal doped [ $n]$ phenancene [36-39], and most recently in p-terphenyl [40] and $p$ quaterphenyl [41] with a record superconducting transition temperature, $T_{\mathrm{c}}$, of $120 \mathrm{~K}$ reaffirms that PAHs are able to exhibit rich electronic band structures and correlations when incorporated with inorganic subunits. The combination of polycyclic aromatics with layered inorganic sheets seem especially suited to admitting superconductivity on quite a high energy scale - and this has been the principal driver in this research. Firstly, the ability to tune the band structure and doping potentially allows the necessary metallic ground state (in the absence of correlations). Then, with multiple bands arising from both substructures we have all the potential ingredients for high-temperature superconductivity: a high electronic density-of-states, high energy phonons associated with $\mathrm{PAH}$, strong electron-phonon coupling arising from the structure-dependent band-structure, and quasi-two-dimensionality. Here, we have combined 3,8-phenanthroline, an analogue of phenanthrene, with $\mathrm{CuMoO}_{4}$ to form an organic-inorganic hybrid compound that shares a similar crystal structure to the previously-reported tetranuclear $\mathrm{Cu}^{2+}$-structured $[\mathrm{Cu}(4,4$ '-bipyridine) $\left.{ }_{0.5} \mathrm{MoO}_{4}\right] \cdot 1.5 \mathrm{H}_{2} \mathrm{O}$ [32]. The parent compound, $\mathrm{CuMoO}_{4}$, is also known for its novel magnetic properties, which are strongly dependent on the variable polymorphic structure and is an example of a " $\mathrm{Cu}^{2+}-\mathrm{d}^{0 \text { " }}$ magnetically-ordered system $[20,21,23]$. While we failed to identify superconductivity in our new hybrid down to $2 \mathrm{~K}$ compared with the bipyridine counterpart, our new hybrid shows an enhanced electronic density-of-states, an antiferromagnetic ground state, and a weak-ferromagnetic ordering below $15 \mathrm{~K}$ most likely due to spin canting. UV-vis diffuse reflectance shows the increased charge carrier concentration changes the electronic band structure and decreases the direct and indirect band-gaps. This supports the use of electron-rich organic spacer molecules in altering the electronic and magnetic behaviour of organicinorganic hybrid materials and should encourage an ongoing search for superconductivity in such systems.

\section{Experimental section}

[Cu(3,8-phenanthroline $\left.)_{0.5} \mathrm{MoO}_{4}\right]$ for structural elucidation was first prepared via hydrothermal reaction of $\mathrm{MoO}_{3}, \mathrm{Cu}_{2} \mathrm{O}, 3,8$-phenanthroline (or phen) and $\mathrm{H}_{2} \mathrm{O}$ using a molar ratio of 0.14:0.14:0.095:277. The reactants were kept in a sealed Teflon-lined stainless-steel autoclave reactor at $160-170^{\circ} \mathrm{C}$ for $72 \mathrm{~h}$ before slowly cooling the autoclave to room temperature. Very thin greenish needle-like crystals of sizes $c a$. $10 \mu \mathrm{m} \times 100 \mu \mathrm{m}$ were obtained upon filtration and several crystallites were selected for single-crystal X-ray diffraction (XRD) characterization. While this method produced sizable single crystals for crystal structure elucidation, the bulk powder was not suitable for magnetization measurements as it contains trace amounts of unreacted $\mathrm{Cu}_{2} \mathrm{O}$, around $23 \%$ by weight, according to powder XRD analysis. Elemental analysis showed the experimental composition $\mathrm{C}=20.05 \%, \mathrm{H}=1.21 \%$ and $\mathrm{N}=3.89 \%$ to be in good agreement with the expected values $\mathrm{C}=20.22 \%$, $\mathrm{H}=1.13 \%$ and $\mathrm{N}=3.93 \%$ for $\left[\mathrm{Cu}\left(\mathrm{C}_{12} \mathrm{H}_{8} \mathrm{~N}_{2}\right)_{0.5} \mathrm{MoO}_{4}\right]$, after taking into account the $23 \mathrm{wt} \%$ of $\mathrm{Cu}_{2} \mathrm{O}$ impurity. A purer powder sample of [Cu (phen) $\left.{ }_{0.5} \mathrm{MoO}_{4}\right]$ was obtained by reacting pre-synthesized $\mathrm{CuMoO}_{4}$ powder with 3,8-phenanthroline and water with the same molar ratio and conditions as mentioned above. $\mathrm{CuMoO}_{4}$ powder was prepared by reacting stoichiometric amounts of $\mathrm{MoO}_{3}$ and $\mathrm{CuO}$ twice at $700{ }^{\circ} \mathrm{C}$ for $72 \mathrm{~h}$ in air with intermediate grinding and pelletizing [20]. Powder XRD (Fig. S1 in SI) shows the resulting $\mathrm{CuMoO}_{4}$ has the lattice parameters of $\alpha-\mathrm{CuMoO}_{4}$ and the resulting hybrid has less than $9 \%$ of unreacted parent compound (asterisks in Fig. S1) in [Cu(phen) $\left.{ }_{0.5} \mathrm{MoO}_{4}\right]$. We show in our magnetization measurements that the parent compound $\alpha-\mathrm{CuMoO}_{4}$ displays no long-range magnetic ordering down to $2 \mathrm{~K}$ that might influence the interpretation of the magnetic data of $\left[\mathrm{Cu}(\mathrm{phen})_{0.5} \mathrm{MoO}_{4}\right]$. Furthermore, our powder XRD and Raman spectroscopic analyses (Figs. S2 and S3) did not indicate the presence of impurity phases that belong to the rich copper (II)-molybdenum (VI) oxide family [42-44], especially lindgrenite, $\mathrm{Cu}_{3}\left(\mathrm{MoO}_{4}\right)_{2}(\mathrm{OH})_{2}$, which displays a magnetic ordering at low temperature. Nor did we find evidence of $\mathrm{Cu}\left(\mathrm{Mo}_{3} \mathrm{O}_{10}\right) \cdot \mathrm{H}_{2} \mathrm{O}$ nor $\mathrm{Cu}_{4} \mathrm{Mo}_{6} \mathrm{O}_{20}$ that might form during hydrothermal synthesis. All the other measurements were carried out on the as-filtered powder product from this second method. The $\left[\mathrm{Cu}\left(4,4^{\prime} \text {-bipyridine }\right)_{0.5} \mathrm{MoO}_{4}\right]$ used in this study was synthesized from the reaction of $\mathrm{Cu}_{2} \mathrm{O}+\mathrm{MoO}_{3}+4,4^{\prime}$-bipyridine (or bpy) $+\mathrm{H}_{2} \mathrm{O}$ (molar ratios: $0.42: 0.42: 0.32: 833$ ) at $160{ }^{\circ} \mathrm{C}$ for $72 \mathrm{~h}$. Unlike $\left[\mathrm{Cu}(\text { phen })_{0.5} \mathrm{MoO}_{4}\right]$, the $\left[\mathrm{Cu}(\mathrm{bpy})_{0.5} \mathrm{MoO}_{4}\right]$ synthesized in this manner contains no $\mathrm{Cu}_{2} \mathrm{O}$ (nor $\mathrm{MoO}_{3}$ ) within the detection limit of our XRD instrument (see Fig. S4), and the XRD pattern matches well with that simulated from single crystal XRD data from Ref. [32]. Note the use of lower valence $\mathrm{Cu}(\mathrm{I})_{2} \mathrm{O}$, as compared with a $\mathrm{Cu}(\mathrm{II})$ starting reagent, in the preparation of phenanthroline and bipyridine hybrid single crystals, was motivated by the opportunity of the low valent $\mathrm{Cu}(\mathrm{I})$ fragment to form species with lower coordination numbers [30], which was the initial motivation of this work. Additional experimental characterization details are available in the Supporting Information (SI) file.

\section{Results and discussion}

$\left.[\mathrm{Cu} \text { (phen })_{0.5} \mathrm{MoO}_{4}\right]$ crystallizes in the triclinic space group $P \overline{1}$, and the asymmetric unit consists of two $\mathrm{Cu}$ and two Mo sites as shown in Fig. 1a. The $\left\{\mathrm{CuMoO}_{4}\right\}$ bimetallic oxide layers are covalently linked through phenanthroline (or phen) ligands to form a 3-dimensional (3D) framework with alternating organic-inorganic regions as shown in Fig. 1b. The bimetallic oxide layers, which propagate across the $a b$ plane, are constructed from $\left\{\mathrm{MoO}_{4}\right\}$ tetrahedra and $\left\{\mathrm{CuO}_{5} \mathrm{~N}\right\}$ octahedra linked through $\{\mathrm{Cu}-\mathrm{O}-\mathrm{Mo}\}$ bridges. Each layer consists of discrete 


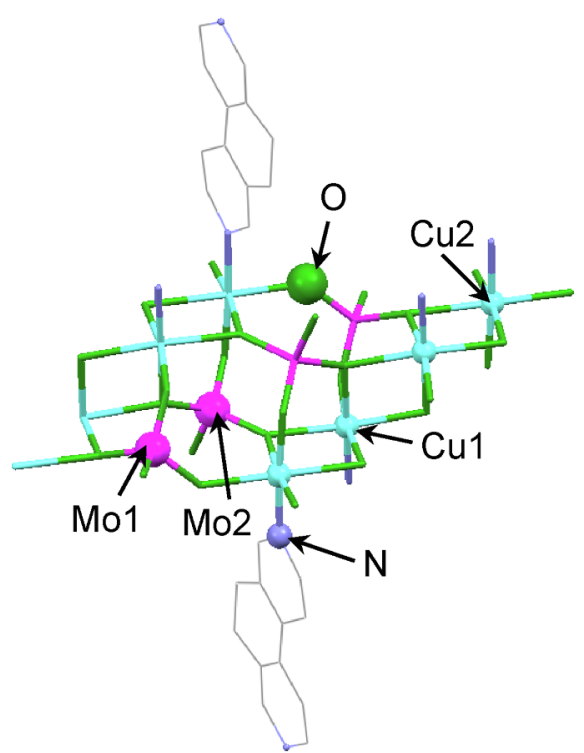

(a)

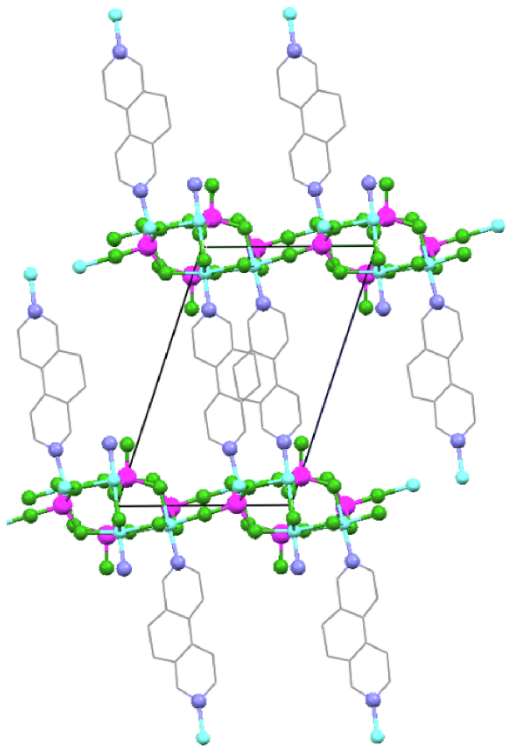

(b)

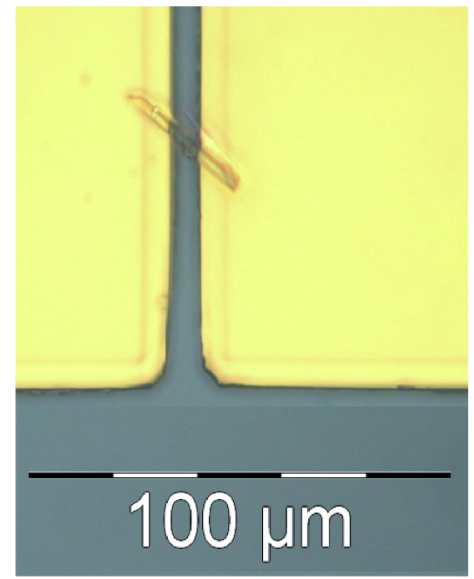

(c)

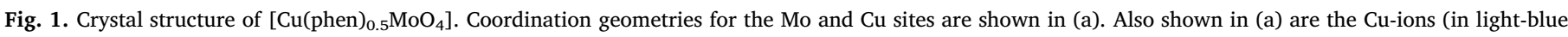

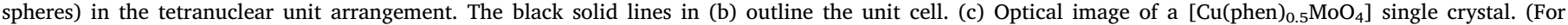
interpretation of the references to colour in this figure legend, the reader is referred to the web version of this article.)

Table 1

Selected crystallographic data for $\left[\mathrm{Cu}(\mathrm{phen})_{0.5} \mathrm{MoO}_{4}\right]$.

\begin{tabular}{ll}
\hline & {$\left[\mathrm{Cu}(3,8-\text { phenan-throline })_{0.5} \mathrm{MoO}_{4}\right]$} \\
\hline Empirical formula & $\mathrm{C}_{6} \mathrm{H}_{4} \mathrm{NCuMoO}_{4}$ \\
Formula weight $\left({\left.\mathrm{g} \cdot \mathrm{mol}^{-1}\right)}\right.$ & 313.59 \\
Crystal system & Triclinic \\
Space group & -- \\
$a(/ \AA)$ & $7.4173(5)$ \\
$b(/ \AA)$ & $9.2259(7)$ \\
$c(/ \AA)$ & $13.8144(10)$ \\
$\alpha\left(/^{\circ}\right)$ & $72.173(8)$ \\
$\beta\left(/^{\circ}\right)$ & $89.886(6)$ \\
$\gamma\left(/{ }^{\circ}\right)$ & $73.221(7)$ \\
$V\left(/ \AA^{3}\right)$ & $857.75(11)$ \\
$Z$ & 4 \\
Density cal. $\left(/ \mathrm{g} \cdot \mathrm{cm}^{-3}\right)$ & 2.436 \\
$\mu\left(/ \mathrm{mm}^{-1}\right)$ & 14.923 \\
$\lambda$, Cu $\mathrm{K}_{\alpha}(/ \AA)$ & 1.5428 \\
$R_{1}[I>2 \sigma(I)], \#$ data & $0.1715,648$ \\
$R_{1}($ all $), \#$ data & $0.3169,1836$ \\
$w R_{2}$ (all data) & 0.4350 \\
Residual density $\left(/ \mathrm{e} \cdot \AA^{\circ} \AA^{3-}\right)$ & $4.30,-1.76$ \\
\hline
\end{tabular}

tetranuclear units of edge-sharing copper oxide $\left\{\mathrm{CuO}_{5} \mathrm{~N}\right\}$ octahedra interconnected by corner-sharing molybdenum oxide $\left\{\mathrm{MoO}_{4}\right\}$ tetrahedra. Similar to $\left[\mathrm{Cu}\left(4,4^{\prime}\right.\right.$-bipyridine) $\left.{ }_{0.5} \mathrm{MoO}_{4}\right] \cdot 1.5 \mathrm{H}_{2} \mathrm{O}$ (herein referred to as $\left.\left[\mathrm{Cu}(\mathrm{bpy})_{0.5} \mathrm{MoO}_{4}\right]\right)$ [32], both hybrids share a common sixmembered $\left\{\mathrm{Cu}_{2} \mathrm{MoO}_{3}\right\}$ and eight-membered $\left\{\mathrm{Cu}_{2} \mathrm{Mo}_{2} \mathrm{O}_{4}\right\}$ ring connectivity within the bimetallic layers. The extra $\mathrm{C}-\mathrm{H}$ atoms of the phen ligand compared to bpy project into the space occupied by the water molecules of the bpy analogue. Table 1 shows the key data collection and refinement details, while selected bond lengths and bond angles for $\left[\mathrm{Cu}(\text { phen })_{0.5} \mathrm{MoO}_{4}\right]$ are summarized in Table $\mathrm{S} 1$ in Supporting Information (SI).

Fig. 2a shows the temperature-dependent magnetic susceptibility $(\chi)$ measurements of a $\left[\mathrm{Cu}(\text { phen })_{0.5} \mathrm{MoO}_{4}\right]$ powder sample for 0.01 and $6 \mathrm{~T}$ applied field. The high temperature $(>100 \mathrm{~K}$ ) susceptibility for both fields are very similar in magnitude and follows the Curie-Weiss law: $\chi=(C /(T-\theta))+\chi_{0}$, where $T$ is the temperature, $C$ is the CurieWeiss constant, $\theta$ is the Weiss temperature and $\chi_{0}$ is the temperature- independent susceptibility. The fitted parameters at higher applied field (6 T), where the high field data has a better signal-to-noise ratio as seen in the $1 /\left(\chi-\chi_{0}\right)$ plot, give $C=0.0357 \mathrm{~K}, \theta=-14.5 \mathrm{~K}$ and $\chi_{0}=2 \times 10^{-5}$. The negative Weiss temperature suggests dominant antiferromagnetic interactions of the $\mathrm{Cu}$ ions. The calculated effective magnetic moment $\left(\mu_{\text {eff }}\right)$ is 1.71(4) $\mu_{\mathrm{B}}$ per $\mathrm{Cu}$ ion. This is close to the theoretical value of $1.73 \mu_{\mathrm{B}}$ for a spin-only $\mathrm{Cu}^{2+}$ free ion. For the isomorphous $\left[\mathrm{Cu}(\mathrm{bpy})_{0.5} \mathrm{MoO}_{4}\right]$ prepared by Rarig and co-workers, no Curie-Weiss regime was observed by the authors, but an antiferromagnetic transition was observed in their $\chi$ versus $T$ plot as a broad peak at $\sim 40 \mathrm{~K}$ [32]. The susceptibility data at $0.01 \mathrm{~T}$ show that this antiferromagnetic transition occurs as a peak at $10.5 \mathrm{~K}$, which is suppressed under a $6 \mathrm{~T}$ magnetic field. AC-susceptibility measurements (Fig. S5) show the absence of a peak in the imaginary and real susceptibility, which indicates that this peak is not associated with a spinglass nor a structural phase transition. The assignment of this peak to an antiferromagnetic ordered state is further confirmed by field-dependent heat capacity measurements, which will be discussed in the heat capacity results section below. Irreversibility is observed in the zero-fieldcooled (ZFC) and field-cooled (FC) branches of the temperature-dependent susceptibility below $0.1 \mathrm{~T}$ (Fig. S5). This is also clearly seen in the field-dependence of the magnetization (Fig. 2b), which shows a small magnetic hysteresis loops at low fields at $10 \mathrm{~K}$ and below. Moreover, the remnant field $\left(M_{\mathrm{r}}\right)$, as shown in Fig. S5, is non-zero below $15 \mathrm{~K}$. This indicates a weak ferromagnetic phase begins below $15 \mathrm{~K}$, and that there are possibly two magnetic orders in our phenhybrid - one commencing just below $15 \mathrm{~K}$ and another below $10 \mathrm{~K}$. As will be presented in the specific heat capacity section below, two heat capacity peaks are clearly seen in the normalized heat capacity plot one at $12.3 \mathrm{~K}$ and another at $7.0 \mathrm{~K}$ (see Fig. $6 \mathrm{c}$ ). Interestingly, the shape of the magnetic hysteresis loops, in particular for 7 and $10 \mathrm{~K}$, has a sharp change in magnetization around $B=0 \mathrm{~T}$. There is also a linear increase in magnetization at higher fields due to the dominant antiferromagnet interactions. These behaviors indicate a possible canting angle in an antiferromagnetic (AFM) coupled system [45-47], which causes weak ferromagnetism. In this scenario, perfect antiparallel alignment of the spins on neighboring metal ions within an AFM layer was not achieved, and a net magnetic order is generated along a 


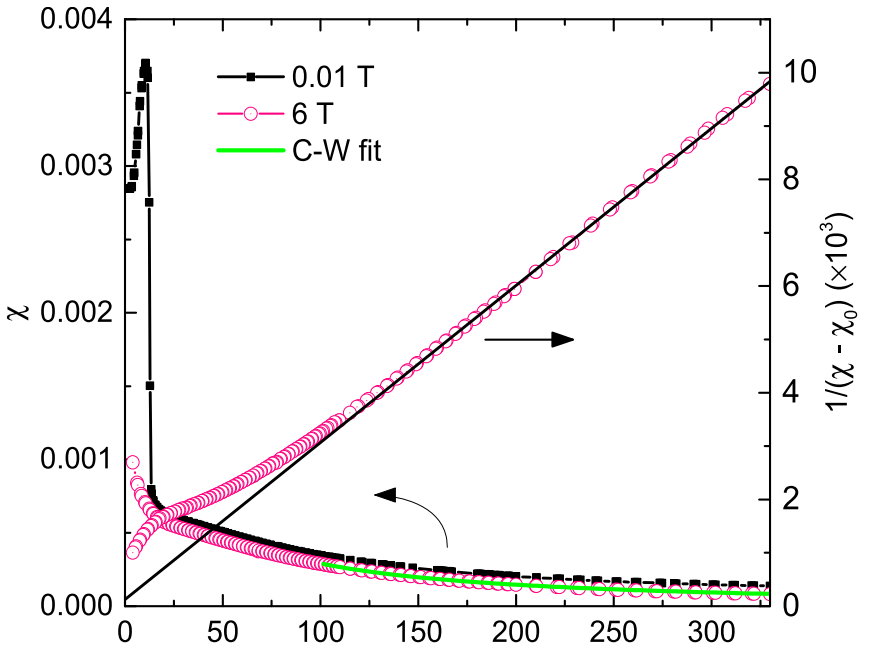

(b)

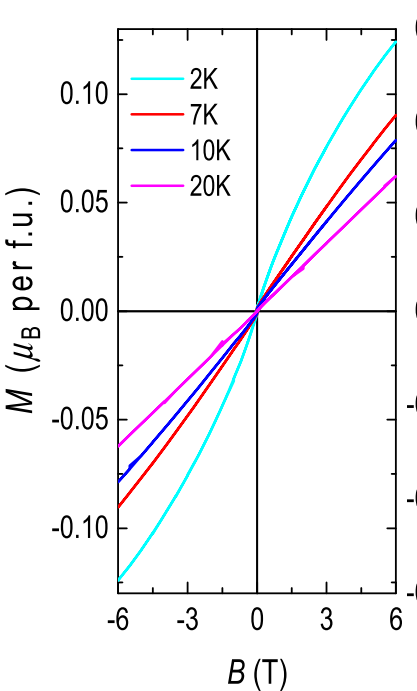

(a)

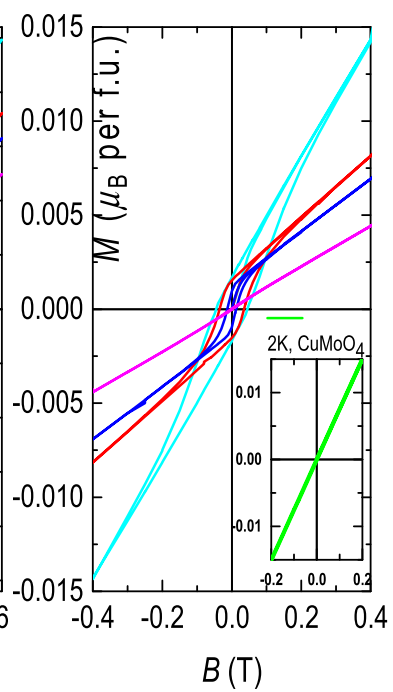

$B(\mathrm{~T})$

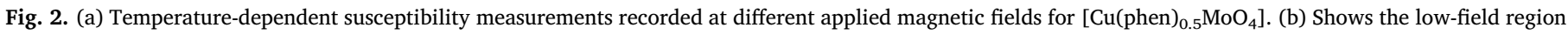

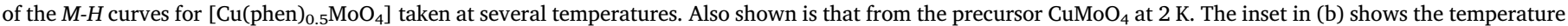
dependence of the remnant field.

particular direction. However, the canting angle $(\varphi)$, estimated from sin $(\varphi)=M_{\mathrm{r}} / M_{\mathrm{s}}$ [45-48] (where $M_{\mathrm{r}}$ is the remnant magnetization at $2 \mathrm{~K}$ from Fig. $5 \mathrm{~S}$, and $M_{s}$ is the theoretical saturation moment for $\mathrm{Cu}^{2+}-$ see below), is less than $0.05^{\circ}$. Therefore, spin canting alone may not be enough to justify the presence of the weak ferromagnetic order. We emphasize that our $\mathrm{CuMoO}_{4}$ precursor has a triclinic, $P \overline{1}, \alpha-\mathrm{CuMoO}_{4}$ crystal structure (Fig. S1) and therefore, as previously reported, do not exhibit any magnetic ordering down to $2 \mathrm{~K}$ [23]. The inset in Fig. 2b shows that our $\mathrm{CuMoO}_{4}$ precursor does not display any hysteresis in its $M-H$ curve, therefore dismissing the possibility of ferromagnetism in $\left.[\mathrm{Cu} \text { (phen) })_{0.5} \mathrm{MoO}_{4}\right]$ originating from a $\mathrm{CuMoO}_{4}$ impurity.

To identify the stable magnetic configurations, theoretical calculations based on the density functional theory (DFT) method were carried out using the VASP package [49]. Atomic positions and lattice parameters were fixed to the experimental result. The exchange-correlation potential was treated by GGA within PBE [50]. Due to the inherent selfinteraction error of DFT, the Hubbard $\mathrm{U}=6.0 \mathrm{eV}$ correction for $\mathrm{Cu} \mathrm{d}$ electrons was additionally considered. We used $400 \mathrm{eV}$ for the energy cutoff and $4 \times 4 \times 2$ k-point grid for the first Brillouin zone, with which the total energy difference between different spin configurations of the $\mathrm{Cu}$ tetramer varied less than $1 \mathrm{meV}$ per unit cell containing four $\mathrm{Cu}$ atoms.

Each $\mathrm{Cu}$ atom is surrounded octahedrally by five $\mathrm{O}$ and one $\mathrm{N}$ atoms with a spin magnetic moment $S=1 / 2$ from $d^{9}$. Four octahedra with edge-sharing comprise one tetramer with the antiferromagnetic coupling between the nearest pair of $\mathrm{Cu}$ spins due to a dominant superexchange interaction through two bridging $\mathrm{O}$ atoms (Fig. 3a). Our calculations indicate that the superexchange strength is much stronger for the central pair than the outer pair. Specifically, the total energy is calculated for three configurations of four Cu spins, $\left(\sigma_{1} \sigma_{2} \sigma_{3} \sigma_{4}\right)=(\uparrow \downarrow \uparrow$ $\downarrow),(\uparrow \uparrow \downarrow \downarrow),(\uparrow \downarrow \downarrow \uparrow)$. Without the Hubbard $U$ correction, the first configuration is most stable, while the second and the third configurations are 6 and $27 \mathrm{meV} /$ u.c. less stable than the first one, respectively. With $U=6 \mathrm{eV}$, the order remains the same with the relative difference changed to 13 and $16 \mathrm{meV} /$ u.c.

For the most stable AFM configuration (Fig. 3a), the band structure and the density of states projected at the $\mathrm{Cu} \mathrm{d}$ orbital and $\mathrm{N}$ are shown in Fig. 3b. Four $\mathrm{Cu} \mathrm{d}$ bands of both spins appear around $2 \mathrm{eV}$ above the Fermi level, while the occupied $\mathrm{Cu} \mathrm{d}$ band appears mainly around -6 to $-4 \mathrm{eV}$ although it is not shown. The valence band states between -4 and $0 \mathrm{eV}$ are mainly contributed by $\mathrm{O}$ p orbitals. The calculated energy gap is $1.2 \mathrm{eV}$, which is smaller than the experimental value $\sim 1.6 \mathrm{eV}$ even with the Hubbard correction $U=6 \mathrm{eV}$. This occurs because of DFT's over-delocalization of $\mathrm{N}$ p driven orbitals, as the conduction band edge states are caused by $\mathrm{N}$ atomic orbitals. For example, when $U=6 \mathrm{eV}$ is hypothetically applied for the $\mathrm{N}$ p, the energy gap becomes $1.4 \mathrm{eV}$, and when the same value for both $\mathrm{N} \mathrm{p}$ and $\mathrm{O}$ p, it further increases to $1.6 \mathrm{eV}$. However, the qualitative feature remains the same as is shown in Fig. $3 \mathrm{~b}$.

In order to explain the observed weak ferromagnetism at $\mathrm{T}<15 \mathrm{~K}$, the effect of electron doping is examined. As shown in Fig. 3c, the configuration $(\uparrow \downarrow \uparrow \downarrow)$ that was most stable at the neutral condition becomes less stable than $(\uparrow \uparrow \downarrow \downarrow)$ when 0.01-0.02 extra electrons per unit cell are added, so that the most stable one is changed to $(\uparrow \uparrow \downarrow \downarrow)$, where $(\uparrow \downarrow \downarrow \uparrow)$ remains less stable due to the relatively stronger AFM coupling of the central pair than that of the outer pairs. Since the extra electron resides mainly on the pyridinic $\mathrm{N}$ atoms, the organic linker is suggested to mediate AFM interlayer-coupling whereby one linker among two in the unit cell $\sigma_{1}$ is coupled to $\sigma_{3}$ while by the other linker $\sigma_{2}$ to $\sigma_{4}$. Thus the weak ferromagnetism might originate from the interlayer AFM coupling assisted by electron doping.

The $M-H$ field loop at $2 \mathrm{~K}$ shows the magnetization increases sharply in the low-field region up to $0.1 \mathrm{~T}$ but does not approach a saturated value even at the highest applied field of $6 \mathrm{~T}$ (Fig. 2c) where it reaches a value of $0.12 \mu_{\mathrm{B}}$ per formula unit (f.u.). Furthermore, all the field-loop plots below $10 \mathrm{~K}$ follow a curvature reminiscent of a Brillouin function, which will be discussed in more detail below. The maximum magnetization value is well below the $1 \mu_{\mathrm{B}}$ /ion value expected for a free $\mathrm{Cu}^{2+}$ magnetic moment given by $g \times J$, where the $g$-factor $=2$ and $J=S$ in spin $1 / 2$. Moreover, it is also less than half of that observed in $\varepsilon$ $\mathrm{CuMoO}_{4}$, a possible triclinic quantum magnet $\left(\sim 0.28 \mu_{\mathrm{B}} /\right.$ f.u. at $1.8 \mathrm{~K}$ and $7 \mathrm{~T}$ ), which displays ferromagnetic-coupled spins below $10 \mathrm{~K}$ in addition to an antiferromagnetically-ordered ground state [23]. The lower-than-expected saturating magnetic moment in our hybrid can be interpreted on the basis of electronic delocalization and localization phenomena. In the presence of electronic delocalization, a (weak) ferromagnetic state is favored at low temperature. However, when localization of electrons sets in, antiferromagnetic ordering is favored at the expense of ferromagnetism. This is exactly what was observed in Fig. 2a and $\mathrm{b}$ where (weak) ferromagnetism occurs (just below $15 \mathrm{~K}$ ) before antiferromagnetism sets in below $10 \mathrm{~K}$. As a result, ferromagnetism cannot fully develop and a lower saturating moment is observed. The 


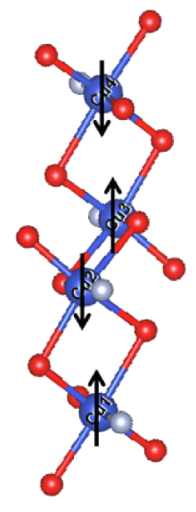

(a)

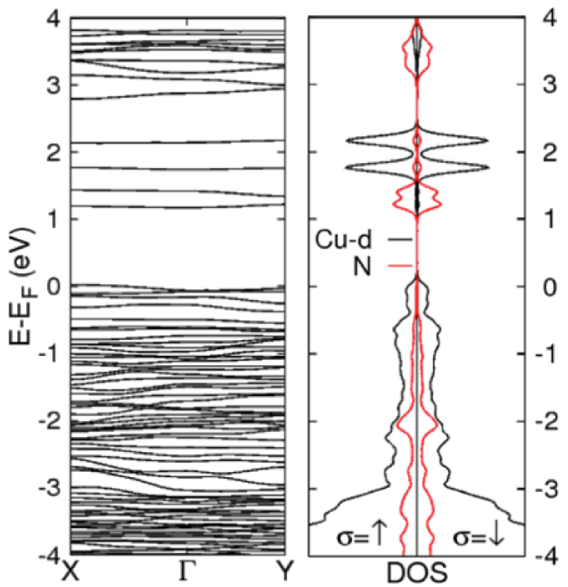

(b)

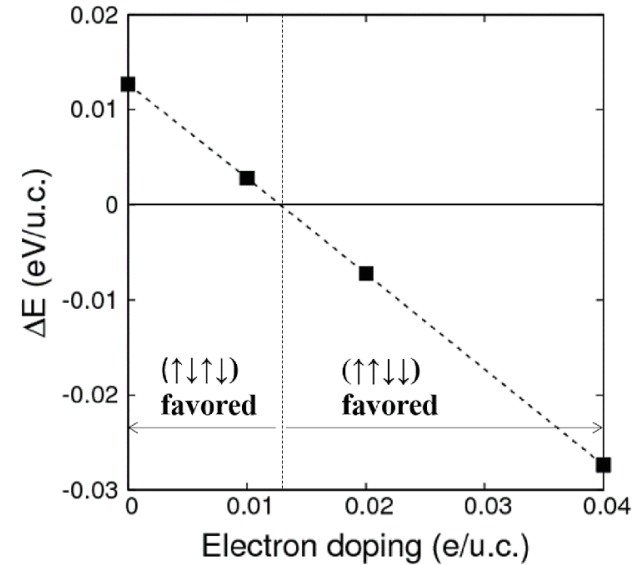

(c)

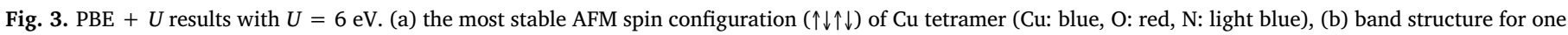

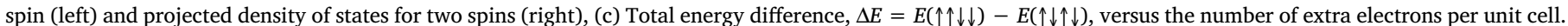
(For interpretation of the references to colour in this figure legend, the reader is referred to the web version of this article.)

same behaviour is also observed in electron-doped manganites where the saturation moment is less than half of the expected $3.6 \mu_{\mathrm{B}} / \mathrm{f}$.u. value [51]. This scenario is also supported by our specific heat data (see below) where magnetic entropy values confirm the presence of both localized and delocalized spins.

The fact that a weak ferromagnetism is observed in $[\mathrm{Cu}$ (phen) $\left.)_{0.5} \mathrm{MoO}_{4}\right]$ but not in the isomorphous $\left[\mathrm{Cu}(\mathrm{bpy})_{0.5} \mathrm{MoO}_{4}\right]$ reported by Rarig et al. (and that prepared in this work) is intriguing. Comparing the nearest $\mathrm{Cu}(n)-\mathrm{Cu}(n)$ and $\mathrm{Cu}(n)-\mathrm{Cu}(n+1)$ distances, we find that these are 3.26 and $3.33 \AA$, respectively for $\left[\mathrm{Cu}(\mathrm{phen})_{0.5} \mathrm{MoO}_{4}\right]$, and 3.29 and $3.31 \AA$, respectively for [Cu(bpy) $\left.{ }_{0.5} \mathrm{MoO}_{4}\right]$ [32]. The differences between these bond distances are small and show no obvious trend. Hence, this cannot explain the difference in magnetic ordering between these two hybrids. Based on the arrangement of the $\mathrm{Cu}$ atoms in $\left.[\mathrm{Cu} \text { (phen })_{0.5} \mathrm{MoO}_{4}\right]$ and the longer interdimer $\mathrm{Cu}-\mathrm{Cu}$ distances (4.92-5.53 $\AA$ ) one might consider the magnetic susceptibility to follow that of dimers of equatorial edge-shared $\left\{\mathrm{CuO}_{5} \mathrm{~N}\right\}$ octahedra linked by molybdate tetrahedra. This can be approximated by an isolated $S=1 / 2$ dimer system such as that observed in $\left[\mathrm{Cu}\left(3,3^{\prime} \text {-bipyridyl }\right)_{0.5} \mathrm{MoO}_{4}\right]$ where this hybrid shows a long-range magnetic ordering below $12 \mathrm{~K}$ [32]. However, attempts to fit the low- and high-field magnetization data in Fig. 2a to the modified Bleaney-Bowers model [52] for spinpairing of two $S=1 / 2$ systems were unsuccessful. Nor does it fit to a linear tetramer model, which takes into account the exchange interactions between the outer-inner and inner-inner $\mathrm{Cu}$ atoms used to describe the magnetization of $\left[\mathrm{Cu}(\mathrm{bpy})_{0.5} \mathrm{MoO}_{4}\right] \cdot 1.5 \mathrm{H}_{2} \mathrm{O}$ [32]. We can therefore conclude that the magnetism in $\left[\mathrm{Cu}(\mathrm{phen})_{0.5} \mathrm{MoO}_{4}\right]$ is different from the $\mathrm{CuMoO}_{4}$-bipyridine-based hybrids. Moreover, the arrangement of $\mathrm{Cu}$ atoms in $\left[\mathrm{Cu}(\text { phen })_{0.5} \mathrm{MoO}_{4}\right]$ is different to that of lindgrenite $\left(\mathrm{Cu}_{3}\left(\mathrm{MoO}_{4}\right)_{2}(\mathrm{OH})_{2}\right.$, which (lindgrenite) as shown in Figs. S2 and S3 is not present in our system, which (lindgrenite) has an equilateral triangular arrangement of $S=1 / 2 \mathrm{Cu}$ atoms and shares a similar magnetic behaviour at low temperature [44]. Interestingly, the incorporation of bipyridine into lindgrenite disrupts the interlayer (magnetic) exchange pathway and the lindgrenite-bipyridine hybrid system is non-ferromagnetic [53]. Since the 3,8-phenanthroline ligands do not influence the coordination preferences of $\mathrm{CuMoO}_{4}$ hybrid (compared with $\left[\mathrm{Cu}(\mathrm{bpy})_{0.5} \mathrm{MoO}_{4}\right]$ ), the magnetic results suggest the electron-richer phenanthroline organic spacers have a defining influence on the magnetic properties of $\left[\mathrm{Cu}(\text { phen })_{0.5} \mathrm{MoO}_{4}\right]$.

Next we consider the origin of electronic delocalization in $[\mathrm{Cu}$ (phen) $\left.{ }_{0.5} \mathrm{MoO}_{4}\right]$ as a result of electron doping from the phenanthroline ligands. We previously showed that layered hybrids of $\mathrm{MoO}_{3}$ containing phenanthroline have a higher electronic density-of-states compared with $\mathrm{MoO}_{3}$ hybrids with bipyridine organic spacer molecules [35]. The higher density-of-states was confirmed by specific heat capacity measurements of the monometallic hybrids. In principle the presence of a larger density of delocalized electrons in $\mathrm{MoO}_{3}$ (phen) $)_{0.5}$ should cause an apparent reduction of $\mathrm{Mo}^{6+}$ species to Mo species with lower oxidation state(s) on the surface (although not a true representation of the bulk). This is indeed what we observed in our X-ray photoelectron spectroscopy (XPS) analysis of $\mathrm{MoO}_{3}$ (phen) 0.5 where the $\mathrm{Mo}^{5+} / \mathrm{Mo}^{6+}$ peak ratio is higher than that of $\mathrm{MoO}_{3}(\mathrm{bpy})_{0.5}$ [54]. We have extended this investigation to our bimetallic hybrids. Fig. 4 shows the Mo 3d XPS of $\left[\mathrm{Cu}(\text { phen })_{0.5} \mathrm{MoO}_{4}\right]$ as well as that of $\left[\mathrm{Cu}(\mathrm{bpy})_{0.5} \mathrm{MoO}_{4}\right]$ (Fig. $4 \mathrm{~d}$ ). The Mo 3d XPS peaks for [Cu(phen) $\left.)_{0.5} \mathrm{MoO}_{4}\right]$ can be fitted to two sets of peaks. One set with the Mo $3 \mathrm{~d}_{5 / 2}$ centred at $232.6 \mathrm{eV}$ is assigned to Mo (VI) oxidation state $[55,56]$, while the other set at lower binding energy is close to a Mo(IV) oxidation state (Mo $3 \mathrm{~d}_{5 / 2}=230.1 \mathrm{eV}$ ) [56,57]. Compared with $\left[\mathrm{Cu}(\mathrm{bpy})_{0.5} \mathrm{MoO}_{4}\right]$ (Fig. 4d), the Mo 3d XPS of this bipyridine hybrid also has two components, but the lower binding energy component has the Mo $3 \mathrm{~d}_{5 / 2}$ peak centred at $231.7 \mathrm{eV}$. This can be assigned to a $\mathrm{Mo}(\mathrm{V})$ species $[56,57]$. Similar to $\mathrm{MoO}_{3}$-phen, the surface state of $\left[\mathrm{Cu}(\text { phen })_{0.5} \mathrm{MoO}_{4}\right]$ is more reduced compared with the bipyridine counterpart, probably due to electron doping from the phenanthroline ligands. The difference in the surface Mo oxidation states of the two bimetallic hybrids is also apparent in their colour difference, and this is clearly seen in the absorption spectra by UV-vis diffuse reflectance measurements, which probe into the bulk. Using the KubelkaMunk function we transformed the diffuse reflectance data (Fig. 5) [58,59], and by setting the exponent $r=1 / 2$ for a direct allowed transition, we found that the optical gap, $E_{\mathrm{op}}$, for $\left[\mathrm{Cu}(\mathrm{phen})_{0.5} \mathrm{MoO}_{4}\right]$ is lower than that of $\left[\mathrm{Cu}(\mathrm{bpy})_{0.5} \mathrm{MoO}_{4}\right]$ (this work), and the $\mathrm{CuMoO}_{4}$ precursor. This trend is unchanged even when the exponent $r=2$ for the case of an indirect allowed transition as shown in Fig. S6. In addition to the difference in surface oxidation state (and colour) as indicated by XPS, the difference in optical absorption of the two hybrids indicates that their (bulk) electronic band structure should be different as well. This difference should be reflected in the electronic density-ofstates, which can be determined by specific heat capacity, which we will present next.

In the absence of electrical transport measurements due to the fragile nature of the crystallites, which easily delaminate, we confirm the presence of free carriers using specific heat measurements [62] on pressed pellet samples. The low-temperature specific heat, $C$, comprises a free carrier electronic term linear in $T$ and a lattice (phonon) term which varies as $T^{3}$, that is, $C=\gamma T+\beta T^{3}$. A plot of $C / T$ versus $T^{2}$ should give a linear slope with a finite non-zero intercept of $\gamma$, the 

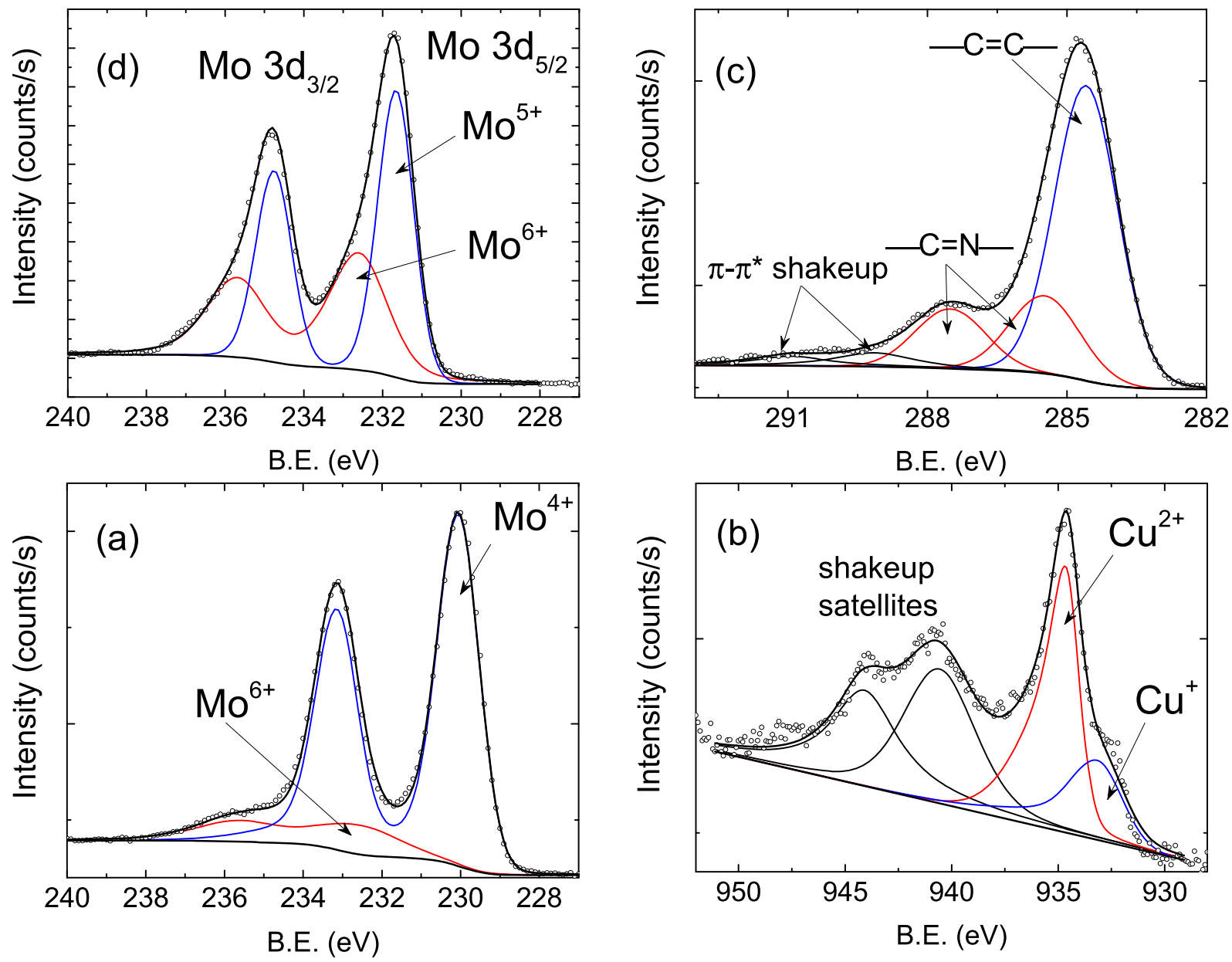

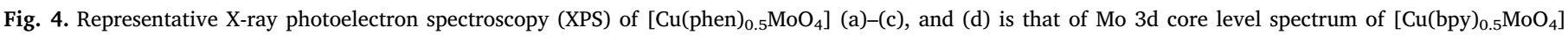

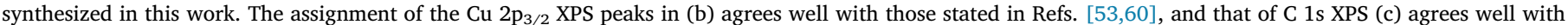
those of nitrogen-containing heterocyclic aromatics [61].

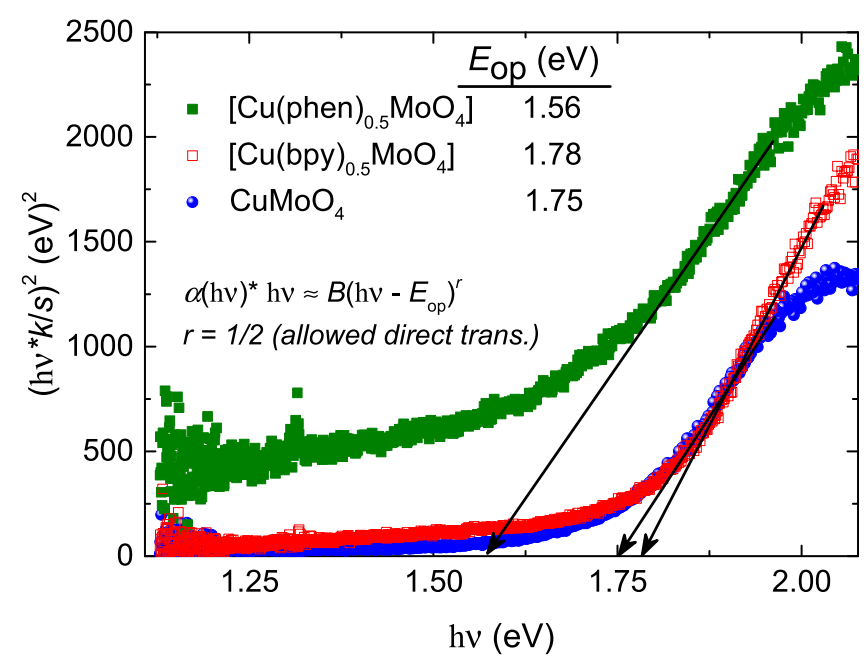

Fig. 5. Kubelka-Munk modified UV-Vis diffuse-reflectance spectra of the phen and bpy copper molybdate hybrids for a direct allowed transition with $r=1 / 2$. Also shown is that of the $\mathrm{CuMoO}_{4}$ precursor.

electronic specific heat coefficient. There is a thermodynamic transition at $T=7 \mathrm{~K}$ (indicated by an arrow in Fig. 6a) in our phenanthroline bimetallic hybrid whose origin is likely to be associated with an antiferromagnetic spin state as observed in the low-field magnetization plot in Fig. 2a. As in the magnetic data, this peak weakens in amplitude under a magnetic field and moves to lower temperature, which is a hallmark of an antiferromagnetic transition [21]. The data between 8 and $12 \mathrm{~K}$ in the $C / T$ versus $T^{2}$ plot (Fig. $6 \mathrm{~b}$ ) can be fitted to a straight line with the intercept $\gamma=94 \mathrm{~mJ} /\left(\mathrm{mol} \cdot \mathrm{K}^{2}\right)$, indicating the presence of free carriers in this material. This value is rather large and should only be compared with $\left[\mathrm{Cu}(\mathrm{bpy})_{0.5} \mathrm{MoO}_{4}\right]$ measured under the same experimental conditions (Fig. S7). The $\gamma$ value of the bipyridine hybrid $\left(68 \mathrm{~mJ} /\left(\mathrm{mol} \cdot \mathrm{K}^{2}\right)\right)$ is lower compared with $\left[\mathrm{Cu}(\mathrm{phen})_{0.5} \mathrm{MoO}_{4}\right]$, which is again consistent with our previously-reported specific heat measurements of $\mathrm{MoO}_{3}$-based hybrids where the phenanthroline-based hybrids have a higher electronic density-of-states compared with bipyridine hybrids [35].

We now consider the entropy due to the antiferromagnetic phase transition resulting from the localized $\mathrm{Cu}^{2+}$ spins. This can be calculated from the specific heat due to magnetism, $C_{\mathrm{m}}$, by first removing the electronic $\left(C_{\mathrm{el}}\right)$ and lattice $\left(C_{\mathrm{lat}}\right)$ contributions to the experimental specific heat data. The $C(T)$ data from 8 to $15 \mathrm{~K}$ were fitted to a polynomial with odd-power terms, $C \approx C_{\mathrm{el}}+C_{\mathrm{lat}}=\gamma^{\prime} T+\beta^{\prime} T^{3}+$ $c T^{5}+d T^{7}$ [63]. The $\gamma^{\prime}$ value obtained from this polynomial fit is within $\pm 20 \mathrm{~mJ} /\left(\mathrm{mol} \cdot \mathrm{K}^{2}\right)$ of the $\gamma$ value (above) and $\beta^{\prime}$ is within \pm $0.5 \mathrm{~mJ} /\left(\mathrm{mol} \cdot \mathrm{K}^{4}\right)$ of $\beta$ obtained from Fig. $5 \mathrm{~b}$. The resulting $C_{\mathrm{m}}$ divided by the temperature, $C_{\mathrm{m}} / T$, was integrated below $15 \mathrm{~K}$ to obtain the magnetic entropy, $S_{\mathrm{m}}=\int_{0}^{T}\left(C_{m} / T\right) \mathrm{d} T$. Shown in Fig. $6 \mathrm{c}$ are the temperature-dependent $C_{\mathrm{m}} / T$ and $S_{\mathrm{m}}$ values for zero field and $0.01 \mathrm{~T}$ below $20 \mathrm{~K}$, where both $S_{\mathrm{m}}$ values are close to each other. The magnetic entropy at zero field, $S_{\mathrm{m}}(0)$, is $0.19 \mathrm{~J} /(\mathrm{mol} \cdot \mathrm{K})$ at $20 \mathrm{~K}$, which corresponds to $3 \%$ of $R \ln (2 S+1)$ where $R$ is the gas constant $(8.314 \mathrm{~J} /(\mathrm{mol} \cdot \mathrm{K}))$ and 

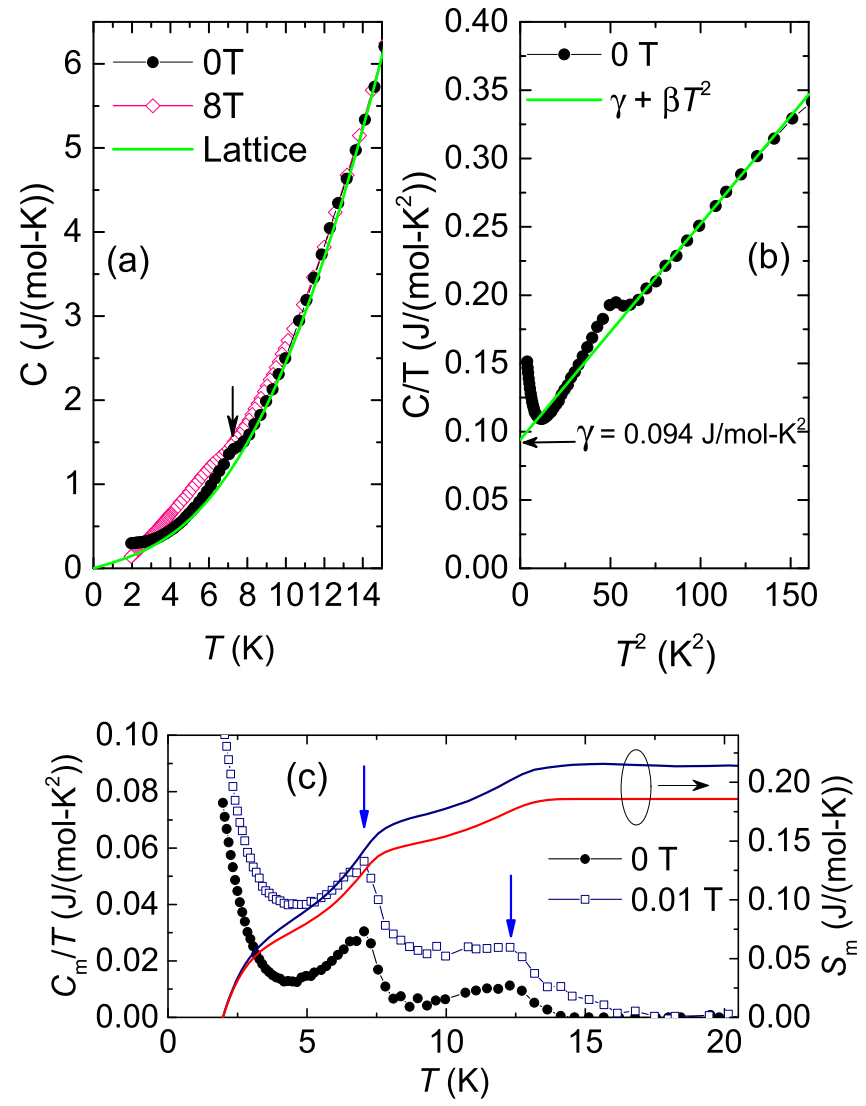

Fig. 6. Low- $T$ region of the zero-field specific heat of a pressed pellet sample of $\left[\mathrm{Cu}(\text { phen })_{0.5} \mathrm{MoO}_{4}\right]$ (a). The arrow indicates the location of antiferromagnetic ordering. Also shown in (a) is the suppression of the magnetic ordering at $8 \mathrm{~T}$ and the fit of the lattice contribution (see text) to the specific heat (solid line). (b) The specific heat plotted as $C / T$ vs $T^{2}$ where the linear extrapolation (solid line) from above $8 \mathrm{~K}$ yields $\gamma=94 \mathrm{~mJ} /\left(\mathrm{mol} \cdot \mathrm{K}^{2}\right)$ and $\beta=1.6 \mathrm{~mJ} /\left(\mathrm{mol} \cdot \mathrm{K}^{4}\right)$. (c) The magnetic contribution to the specific heat, $C_{\mathrm{m}}$, (left axis plotted as $C_{\mathrm{m}} / T$ ) and the magnetic entropy, $S_{\mathrm{m}}$ (right axis), as a function of temperature. The blue arrows indicate the positions of the ferromagnetic and antiferromagnetic transition. (For interpretation of the references to colour in this figure legend, the reader is referred to the web version of this article.)

$S$ is in spin $1 / 2$. This means $3 \%$ of $\mathrm{Cu}^{2+}$ spins undergo magnetic ordering at zero field, are localized, and the rest of the spins are delocalized. The presence of residual delocalized carriers is also indicated by the fact that if we fit a power law divergence to the zero-field $C_{\mathrm{m}} / T$ data in Fig. $6 c$ and subtract, we find the overall entropy balance for the two magnetic transitions with a residual value at $T=0$ of $13 \mathrm{~mJ} /$ $\left(\mathrm{mol} \cdot \mathrm{K}^{2}\right.$ ), that is, only a small part of the total of $94 \mathrm{~mJ} /\left(\mathrm{mol} \cdot \mathrm{K}^{2}\right.$ ) (see Fig. S7c). In comparison, $\left[\mathrm{Cu}(\mathrm{bpy})_{0.5} \mathrm{MoO}_{4}\right] \cdot 1.5 \mathrm{H}_{2} \mathrm{O}$ is antiferromagnetically ordered at low temperatures according to Ref. [32], but for the $\left[\mathrm{Cu}(\mathrm{bpy})_{0.5} \mathrm{MoO}_{4}\right]$ prepared in this work, this was found at $3 \mathrm{~K}$ from our specific heat measurements (Fig. S7). On closer examination, we found that the specific heat jump in our bipyridine hybrid is higher $(\Delta C \sim 0.41 \mathrm{~J} /(\mathrm{mol}-\mathrm{K}))$ compared with that of our phenanthrene hybrid $(\Delta C \sim 0.21 \mathrm{~J} /(\mathrm{mol}-\mathrm{K})$ ). This, together with a smaller $\gamma$ value and the fact that the Mo species in the bipyridine hybrid are more oxidized (from XPS), strongly indicate the presence of more localized spins in $\left[\mathrm{Cu}(\mathrm{bpy})_{0.5} \mathrm{MoO}_{4}\right]$.

\section{Conclusions}

A novel layered organic-inorganic hybrid material $[\mathrm{Cu}(3,8$ phenanthroline) ${ }_{0.5} \mathrm{MoO}_{4}$ ] has been prepared and characterized by a variety of experimental techniques. Structural analysis confirms that the inorganic layers, consisting of molybdate tetrahedra corner-shared with clusters of edge-sharing $\left\{\mathrm{CuO}_{5} \mathrm{~N}\right\}$ octahedra, are covalently interlinked by 3,8-phenanthroline molecules. Heat capacity and magnetic measurements show that the use of electron-rich rigid phenanthroline organic spacer molecules has a significant impact on the electronic and magnetic properties of copper molybdate hybrid materials. As a result, $\left[\mathrm{Cu}(3,8 \text {-phenanthroline })_{0.5} \mathrm{MoO}_{4}\right]$ has an antiferromagnetic ground state with weak ferromagnetism at low temperature. Furthermore, its electronic specific heat coefficient is non-zero and is larger than that of the isotypic bipyridine hybrid confirming the presence of a higher concentration of free carriers in the phenanthroline system. Theoretical calculations based on the density functional theory (DFT) method indicate that the weak ferromagnetism originates from interlayer coupling assisted by electron doping. Reduced surface oxidation states and optical band gap energy in $\left[\mathrm{Cu}(3,8 \text {-phenanthroline })_{0.5} \mathrm{MoO}_{4}\right]$, compared with $\mathrm{CuMoO}_{4}$ and the isotypic bipyridine hybrid, also suggest charge carrier injection facilitated by 3,8-phenthroline. The presence of a large amount of delocalized spins was confirmed by the calculated specific heat magnetic entropy, which accounts to around 3\% localized spins. Therefore, we propose that the weak ferromagnetism has its origin from interlayer AFM coupling assisted by electron doping, and a slight canting angle in an AFM coupled system. This study opens up intriguing prospects for preparing a new class of layered hybrid materials with tunable structural, optical, electronic and magnetic properties.

\section{CRediT authorship contribution statement}

Islah-u-din: Conceptualization, Methodology, Data curation, Investigation, Writing - original draft, Funding acquisition. Shen V. Chong: Conceptualization, Methodology, Data curation, Investigation, Validation, Writing - original draft. Geoffrey B. Jameson: Investigation, Formal analysis, Writing - review \& editing. Sebastiampillai G. Raymond: . Geunsik Lee: . In K. Park: . Xiaolin Wang: Data curation, Writing - review \& editing. Mark R. Waterland: Supervision, Investigation, Data curation, Resources. Jeffery L. Tallon: Conceptualization, Supervision, Resources, Funding acquisition, Writing - review \& editing.

\section{Declaration of Competing Interest}

The authors declare that they have no known competing financial interests or personal relationships that could have appeared to influence the work reported in this paper.

\section{Acknowledgements}

We acknowledge funding support from the Marsden Fund of New Zealand (grant IRL0501) and from the MacDiarmid Institute for Advanced Materials and Nanotechnology for the Spider X-ray detector and for research support. The Higher Education Commission, Pakistan, provided a doctoral scholarship for I.U. I.U. would also like to acknowledge Professor Shane G. Telfer (Massey University) for his guidance and advice on the synthesis of these hybrids. The authors would also like to thank Prof. Grant Williams (Victoria University of Wellington) for his assistance with the interpretation of the magnetic data.

\section{Appendix A. Supplementary data}

CCDC\#1587999 contains the supplementary crystallographic data for this paper. These data can be obtained free of charge from The Cambridge Crystallographic Data Centre via www.ccdc.cam.ac.uk/ data_request/cif. Supplementary data to this article can be found online at https://doi.org/10.1016/j.jmmm.2020.166881. 


\section{References}

[1] M.S. Saveleva, K. Eftekhari, A. Abalymov, T.E.L. Douglas, D. Volodkin, B.V. Parakhonskiy, A.G. Skirtach, Front. Chem. 7 (2019) 1.

[2] M.M. Adnan, A.R.M. Dalod, M.H. Balci, J. Glaum, M.A. Einarsrud, Polymers 10 (2018) 1129.

[3] S.M. Mir, L.A. Nagahara, T. Thundat, P. Mokarian-Tabari, H. Furukawa, A. Khosla, J. Electrochem. Soc. 165 (2018) 3137.

[4] R. Mobin, T.A. Rangreez, H.T. Chisti, Inamuddin, M. Rezakazmi, Organic-inorganic hybrid materials and their applications, in: M.M. Jafar, H. Sheardown, A. Al-Ahmed (Eds.), Functional Polymers. Polymers and Polymeric Composites: A Reference Series, Springer, Cham, 2019, pp. 1137-1156.

[5] P.J. Hagrman, D. Hagrman, J. Zubieta, Angew. Chem. Int. Ed. 38 (1999) 2638.

[6] K. Thirumal, W.K. Chong, W. Xie, R. Ganguly, S.K. Muduli, M. Sherburne, M. Asta, S. Mhaisalkar, T.C. Sum, H.S. Soo, N. Mathews, Chem. Mater. 29 (2017) 3947.

[7] P.-F. Li, Y.-Y. Tang, W.-Q. Liao, H.-Y. Ye, Y. Zhang, D.-W. Fu, Y.-M. You, R.G. Xiong, NPG Asia Mater. 9 (2017) e342.

[8] M.-P. Santoni, G.S. Hanan, B. Hasenknopf, Coord. Chem. Rev. 281 (2014) 64.

[9] W. Li, Z. Wang, F. Deschler, S. Gao, R.H. Friend, A.K. Cheetham, Nat. Rev. Mater. 2 (2017) 16099.

[10] B. Saparov, D.B. Mitzi, Chem. Rev. 116 (2016) 4558.

[11] H. Hu, B. Dong, W. Zhang, J. Mater. Chem. A 5 (2017) 11436.

[12] L. Pedesseau, D. Sapori, B. Traore, R. Robles, H.-H. Fang, M.A. Loi, H. Tsai, W. Nie, J.-C. Blancon, A. Neukrich, S. Tretiak, A.D. Mohite, C. Katan, J. Evan, M. Kepenekian, ACS Nano 10 (2016) 9776.

[13] P.G. Chigrin, N.V. Lebukhova, A.Yu. Ustinov, React. Kinet. Mech. Catal. 113 (2014) 1

[14] R. Maggiore, S. Galvagno, J.C.J. Bart, A. Giannetto, G. Toscano, Z. Phys. Chem. 132 (1982) 85.

[15] L. Robertson, N. Penin, V. Blanco-Gutierrez, D. Sheptyakov, A. Demourguesa, M. Gaudon, J. Mater. Chem. C 3 (2015) 2918;

M. Gaudon, P. Deniard, A. Demourgues, A.-E. Thiry, C. Carbonera, A.L. Nestour, A. Largeteau, J.-F. Létard, S. Jobic, Adv. Mater. 19 (2007) 3517.

[16] A.-E. Thiry, M. Gaudon, C. Payen, N. Daro, J.-F. Létard, S. Gorsse, P. Deniard, X. Rocquefelte, A. Demourgues, M.-H. Whangbo, S. Jobic, Chem. Mater. 20 (2008) 2075.

[17] F. Rodríguez, D. Hernández, J. Garcia-Jaca, H. Ehrenberg, H. Weitzel, Phys. Rev. B 61 (2000) 16497.

[18] T. Ito, H. Takagi, T. Asano, Chem. Mater. 21 (2009) 3376.

[19] G. Steiner, R. Salzer, W. Reichelt, Fresenius J. Anal. Chem. 731 (2001) 731.

[20] H. Ehrenberg, H. Weitzel, H. Paulus, M. Wiesmann, G. Wltschek, M. Geselle, H. Fuess, J. Phys. Chem. Solids 58 (1997) 153.

[21] S. Haravifard, K. Fritsch, T. Asano, J.P. Clancy, Z. Yamani, G. Ehlers, T. Nishimura, Y. Inagaki, T. Kawae, I. Swainson, B.D. Gaulin, Phys. Rev. B 84 (2011) 094436.

[22] T. Asano, T. Nishimura, S. Ichimura, Y. Inagaki, T. Kawae, T. Fukui, Y. Narumi, K. Kindo, T. Ito, S. Haravifard, B.D. Gaulin, J. Phys. Soc. Jpn. 80 (2011) 093708.

[23] J. Baek, A.S. Sefat, D. Mandrus, P.S. Halasyamani, Chem. Mater. 20 (2008) 3785

[24] G.A. Senchyk, A.B. Lysenko, K.V. Domasevitch, O. Erhart, S. Henfling, H. Krautscheid, E.B. Rusanov, K.W. Krämer, S. Decurtins, S.-X. Liu, Inorg. Chem. 56 (2017) 12952.

[25] H.I. Buvailo, V.G. Makhankova, V.N. Kokozay, I.V. Omelchenko, O.V. Shishkin, D. Matoga, J. Jezierska, Inorg. Chim. Acta 443 (2016) 36.

[26] N. Alam, C. Feldmann, Z. Anorg. Allg. Chem. 636 (2010) 437.

[27] R.-Q. Fang, Y.-F. Zhao, X.-M. Zhang, Inorg. Chim. Acta 359 (2006) 2023.
[28] Y. Xu, J. Lu, N.K. Goh, J. Mater. Chem. 9 (1999) 1599.

[29] D.J. Chesnut, D. Hagrman, P.J. Zapf, R.P. Hammond, R. LaDuca Jr., R.C. Haushalter, J. Zubieta, Coord. Chem. Rev. 190-192 (1999) 737-769.

[30] D. Hagrman, P.J. Hagrman, J. Zubieta, Comments Inorg. Chem. 21 (1999) 225.

[31] D. Hagrman, J. Zubieta, Trans. Am. Crystallogr. Assoc. 33 (1998) 105.

[32] R.S. Rarig, R. Lam, P.Y. Zavalij, J.K. Ngala, R.L. LaDuca, J.E. Greedan, J. Zubieta, Inorg. Chem. 41 (2002) 2124.

[33] D. Hagrman, C.J. Warren, R.C. Haushalter, C. Seip, C.J. O'Connor, R.S. Rarig Jr., K.M. Johnson III, R.L. LaDuca Jr., J. Zubieta, Chem. Mater. 10 (1998) 3294.

[34] B.C. Schwarz, H. Ehrenberg, H. Weitzel, H. Fuess, Inorg. Chem. 46 (2007) 378.

[35] S.V. Chong, Islah-u-din, J.L. Tallon, Mater. Lett. 204 (2017) 141.

[36] X.F. Wang, R.H. Liu, Z. Gui, Y.L. Xie, Y.J. Yan, J.J. Ying, X.G. Luo, X.H. Chen, Nat. Commun. 2 (2011) 507.

[37] R. Mitsuhashi, Y. Suzuki, Y. Yamanari, H. Mitamura, T. Kambe, N. Ikeda, H. Okamoto, A. Fujiwara, M. Yamaji, N. Kawasaki, Nature 464 (2010) 76.

[38] Y. Kubozono, H. Mitamura, X. Le, X. He, Y. Yamanari, Y. Takahashi, Y. Suzuki, Y. Kaji, R. Eguchi, K. Akaike, T. Kambi, H. Okamoto, A. Fujiwara, T. Kato, T. Kosugi, H. Aoki, Phys. Chem. Chem. Phys. 13 (2011) 16476.

[39] M. Xue, T. Cao, D. Wang, Y. Wu, H. Yang, X. Dong, J. He, F. Li, G.F. Chen, Sci. Rep. 2 (2012) 389.

[40] R.-S. Wang, Y. Gao, Z.-B. Huang, X.-J. Chen, 2017 arXiv:cond-mat/1703.06641.

[41] W. Liu, H. Lin, R. Kang, X. Zhu, Y. Zhang, S. Zheng, H.-H. Wen, Phys. Rev. B 96 (2017) 224501.

[42] A. Moini, R. Peascoe, P.R. Rudolf, A. Clearfield, Inorg. Chem. 25 (1986) 3782.

[43] C. Tian, E. Wang, Y. Li, L. Xu, C. Hu, J. Peng, J. Solid State Chem. 177 (2004) 839.

[44] S. Vilminot, G. André, M. Richard-Plouet, F. Bourée-Vigneron, M. Kurmoo, Inorg. Chem. 45 (2006) 10938.

[45] S.-H. Park, I.-H. Oh, S. Park, Y. Park, J.H. Kim, Y.-D. Huh, Dalton Trans. 41 (2012) 1237.

[46] X.-Y. Wang, Z.-M. Wang, S. Gao, Inorg. Chem. 47 (2008) 5720.

[47] R. Feyerherm, A. Loose, T. Ishida, T. Nogami, J. Kreitlow, D. Baabe, F.J. Litterst, S. Süllow, H.-H. Klauss, Phys. Rev. B 69 (2004) 134427.

[48] D.-F. Weng, Z.-M. Wang, S. Gao, Chem. Soc. Rev. 40 (2011) 3157.

[49] G. Kresse, J. Furthmuller, Comput. Mater. Sci. 6 (1996) 15.

[50] J.P. Perdew, K. Burke, M. Ernzerhof, Phys. Rev. Lett. 77 (1996) 3865.

[51] A. Maignan, C. Martin, F. Damay, B. Raveau, Chem. Mater. 10 (1998) 950.

[52] B. Bleaney, K.D. Bowers, Proc. R. Soc. Lond. A 214 (1952) 451.

[53] M.P. Shores, B.M. Bartlett, D.G. Nocera, J. Am. Chem. Soc. 127 (2005) 17986.

[54] S.V. Chong, G.B. Jameson, Islah-u-din, M.R. Waterland, J.L. Tallon, Mater. Lett. 231 (2018) 187.

[55] J.H. Shin, Q.M. Wang, K.H. Kim, Mater. Chem. Phys. 130 (2011) 870.

[56] J. Baltrusaitisa, B. Mendoza-Sanchez, V. Fernandez, R. Veenstrab, N. Dukstiene, A. Roberts, N. Fairley, Appl. Surf. Sci. 326 (2015) 151.

[57] P.A. Spevack, N.S. McIntyre, J. Phys. Chem. 97 (1993) 11020.

[58] R. López, R. Gómez, J. Sol-Gel Sci. Technol. 61 (2012) 1.

[59] J.D. Lindberg, D.G. Snyder, Appl. Opt. 12 (1973) 573.

[60] J. Haber, T. Machej, L. Ungier, J. Ziółkowski, J. Solid State Chem. 25 (1978) 207.

[61] K. Roodenko, M. Gensch, J. Rappich, K. Hinrichs, N. Esser, R. Hunger, J. Phys. Chem. B 111 (2007) 7541.

[62] For example, see, N.W. Ashcroft, N.D. Mermin, Solid State Physics, Holt, Rinehart and Winston, New York, 1976, pp. 46-49.

[63] H.-F. Zhai, Z.-T. Tang, H. Jiang, K. Xu, K. Zhang, P. Zhang, J.-K. Bao, Y.-L. Sun, W.H. Jiao, I. Nowik, I. Felner, Y.-K. Li, X.-F. Xu, Q. Tao, C.-M. Feng, Z.-A. Xu, G.H. Cao, Phys. Rev. B 90 (2014) 064518. 